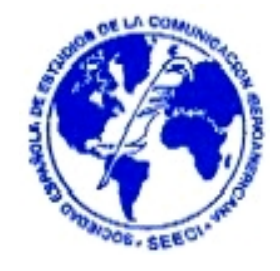

\title{
EL CANAL DE PANAMÁ Y EL COMERCIO REGIONAL DE AMÉRICA LATINA Y EL CARIBE: ¿FUTUROS DEPENDIENTES?
}

\section{THE PANAMA CANAL AND REGIONAL TRADE OF LATIN AMERICA AND THE CARIBBEAN: DEPENDENT FUTURE?}

\section{AUTORA}

\section{Sara Fernández Penit}

Economía Internacional. Universidad Complutense de Madrid (España).

safepe@hotmail.com

\section{RESUMEN}

EEUU es el país que más uso da al Canal de Panamá, por delante de Asia. LatinoAmérica también es muy dependiente de éste. El aumento del transporte de mercancías logra que en el mercado sudamericano exista una mayor diversificación.

\section{PALABRAS CLAVE}

Canal - Panamá - Mercancías - Transporte

\section{ABSTRACT}

The U.S. is the country that use the Panama Canal da, ahead of Asia. Latin America is also very dependent on it. The increase in freight achieved in the South American market there is greater diversification. 
REVISTA DE LA SEECI.

Fernández Penit, Sara (2000): El canal de Panamá y el comercio regional de América Latina y el Caribe: ¿Futuros dependientes? No 6. Noviembre. Año IV. Páginas: 60-69.

ISSN: 1576-3420 DOI: http://dx.doi.org/10.15198/seeci.2000.6.60-69

\section{KEY WORDS}

Canal - Panama - Goods - Transportation

ÍNDICE

1. Introducción.

2. Justificación del análisis.

3. Comercio intralatinoamericano en los tránsitos canaleros.

4. Conclusiones.

\section{Introducción}

Tal como establecen los Tratados Torrijos-Carter, al mediodía del 31 de diciembre de 1999, EEUU traspasará la administración del Canal de Panamá a la República de Panamá. Son diversas las incertidumbres que se plantean $y$, toma vigencia la discusión sobre la capacidad de esta vía de transporte. Resulta pertinente profundizar en el significado de esta vía acuática para las partes implicadas, con el fin de justificar las oportunas actuaciones. En este trabajo llevo a cabo una caracterización del comercio regional de América Latina y el Caribe vinculado al canal de Panamá en el período 1985-1996. 


\section{Justificación del análisis}

Si bien los cambios acaecidos en la naturaleza de los flujos comerciales han sido diversos, la estructura del comercio vinculado al canal de Panamá se ha caracterizado por la estabilidad desde la fecha en que aquel entrara en funcionamiento, el 15 de agosto de 1914.

En la década presente, se vienen detectando cambios en usuarios, mercancías, e inclusive en la marina mercante, junto a los estudios de proyección de tráfico llevados a cabo por la Comisión del Canal de Panamá, se han realizado diversos análisis en los que se comparte que el Canal de Panamá puede afrontar dificultades de capacidad en un futuro próximo ${ }^{1}$

Si consideramos la vinculación de los Estados Unidos, Asia, América Latina, Europa, Canadá, Oceanía, África y Oriente Medio al canal, se constata que este orden, en cuanto a protagonismo en los tránsitos canaleros, se mantiene para el período 19851996. Como excepción, el aumento de protagonismo de América Latina en detrimento de Asia en el ejercicio de $1996^{2}$.

Estados Unidos se vincula a más del $70 \%$ de la carga comercial que atraviesa el Canal. Asia aparece implicada en más del $44 \%$ de la carga durante el período de análisis. Europa, si bien en la primera mitad del espacio temporal considerado tiende a aumentar su participación en la carga total que atraviesa el Canal, en la segunda

\footnotetext{
$1 \quad$ Véase conclusiones de estudios en, Comisión Europea (1998), Compendio del Congreso Universal del Canal de Panamá, 7-10 de septiembre de 1997. Melba, A. Raven y Gloria Manfredo. Págs. 67-95, Panamá.

La vinculación del comercio de las distintas regiones al canal da apoyo en el análisis de los informes anuales de la Comisión del Canal de Panamá para los ejercicios fiscales 1985-1996. El ejercicio fiscal no coincide con el año natural. Así, el ejercicio fiscal de 1996 se refiere al período oct. de 1995-sep. de 1996.
} 
mitad pierde protagonismo. Con relación a América Latina, esta región se vincula a más del 37\% de la carga que transita el Canal de Panamá. Aunque en la primera mitad del período se observa una tendencia a disminuir su participación, en el período 1991-1996 tiene lugar una mantenida tendencia alcista. Concluye el período con una participación del 50,1\% frente a la participación del 44,3\% de 1985.

En el gráfico no 1, se observa que los tránsitos canaleros vinculados a América Latina se incrementaron hasta situarse en los últimos ejercicios en unos niveles muy superiores a los que iniciaron el período. La estabilidad de tales flujos se altera en el ejercicio de 1990, en el que se inicia una tendencia alcista. Esta tendencia se acentúa hacia 1993, ejercicio a partir del cual la pendiente de la curva es mucho más pronunciada.

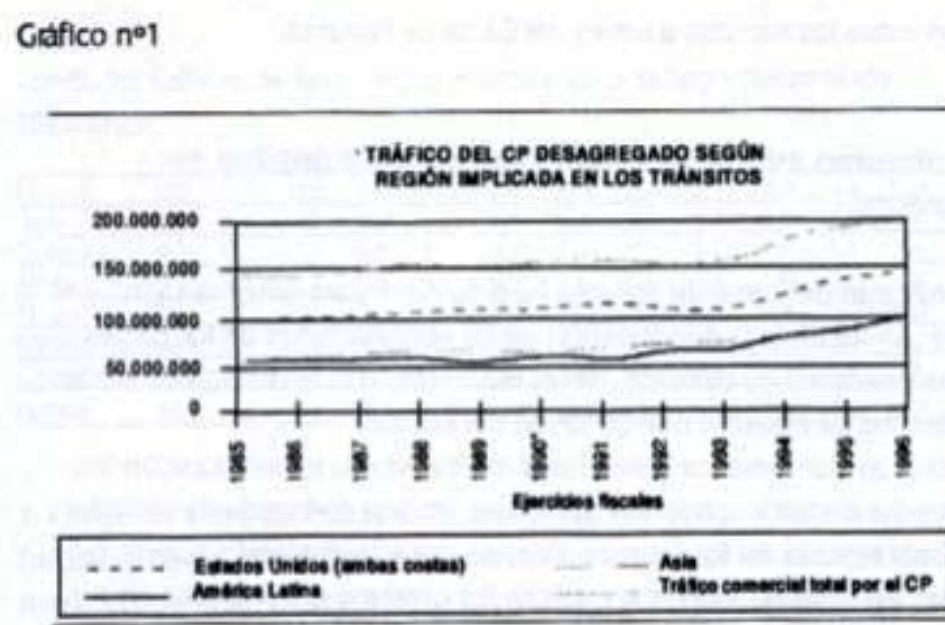

Fuente: Comistón dei Canal de Panama (infornes anuaies de los ejerdodos fiscales 1985. 19961. Elaboradón proola.

Coincide esto último con el comportamiento seguido por la curva que se refiere al tráfico comercial total por el canal, lo que lleva a pensar que el comercio 
latinoamericano contribuye a explicar, en gran medida, la tendencia creciente en tonelaje que tiene lugar desde el ejercicio de 1993 en aquel.

Por otra parte, las pendientes menos acentuadas para las curvas que se vinculan a Estados Unidos y Asia a partir de tal ejercicio, sugieren que una de las claves en las nuevas tendencias asociadas a los tránsitos del Canal de Panamá se encuentra en la vinculación del comercio intralatinoamericano a esta vía interoceánica.

Los recientes cambios en las economías latinoamericanas y del Caribe, tras una década de los ochenta poco alentadora, se están dejando sentir en la mayor presencia de esta región en los flujos comerciales. A partir de los datos indicados puede indicarse que ello está teniendo una repercusión sobre los tránsitos del Canal de Panamá.

\section{Comercio intralatinoamericano en los tránsitos canaleros}

El significado del canal de Panamá ha sido clave para América Latina y el Caribe. Ahora bien, la dependencia de las exportaciones de los países latinoamericanos no coincide, necesariamente con el protagonismo de los tránsitos de aquellos que se sirven del $\mathrm{Canal}^{33}$. El hecho de que América Latina haya mantenido su especialización productiva ha derivado, en líneas generales, en una demanda de servicios del Canal estable. En los últimos años, se van introduciendo nuevas tendencias en la producción que explican los cambios estructurales en sus exportaciones. Ello es favorecido por los recientes procesos de integración 
REVISTA DE LA SEECI.

Fernández Penit, Sara (2000): El canal de Panamá y el comercio regional de América Latina y el Caribe: ¿Futuros dependientes? No 6. Noviembre. Año IV. Páginas: 60-69.

ISSN: 1576-3420 DOI: http://dx.doi.org/10.15198/seeci.2000.6.60-69

latinoamericanos, dirigidos por los gobiernos, y por los procesos de industrialización latinoamericana liderados por un número reducido de empresas nacionales que se orientan hacia las actividades más dinámicas ${ }^{4}$.

La pregunta pertinente para el análisis que se desarrolla es, en el período 1985-1996 ¿las tendencias generales indicadas, se reflejan en los tránsitos por el Canal? ${ }^{55}$. En el cuadro $n-1$, puede constatarse que, durante el período analizado, es el comercio intrarregional el que protagoniza la evolución de todo el comercio latinoamericano vinculado al Canal de Panamá. Además, se invierte la previa tendencia depresiva en 1991.

\begin{tabular}{|c|c|c|c|c|c|c|c|c|c|c|c|c|}
\hline & 1985 & 1986 & 1997 & 1988 & 1989 & 1990 & 1991 & 1992 & 1993 & 1994 & 1995 & 1996 \\
\hline EuropA & 13,0 & 14,9 & 16.6 & 15.9 & 16,6 & 15.2 & 15,8 & 14,4 & 15,1 & 14,3 & 14,8 & 12,4 \\
\hline As & 90 & 6.4 & 9.2 & 100 & 9.2 & 9.2 & 8.7 & 9.1 & 8.5 & 6.6 & 68 & 6,6 \\
\hline OMedio & 0,2 & 0,2 & 0,3 & 0,4 & 0,2 & 0,2 & 0,3 & 0,3 & 0,2 & 0,5 & 0,3 & 1,1 \\
\hline Aftea & 0.2 & 0.5 & 0.5 & 0.8 & 1,5 & 08 & 1,3 & 0,7 & 0,8 & 1,4 & 1,7 & 0,4 \\
\hline EE.UI & 28 & 29.3 & 29.9 & 29,3 & 35,8 & 18,3 & 34.6 & 31.7 & 29.2 & 33,8 & 33,2 & 34,3 \\
\hline canads & 2.4 & 24 & 1.8 & 2.0 & 20 & 1.6 & 2.2 & 30 & 3.4 & 3.1 & 24 & 27 \\
\hline Goeania & 0.8 & 0.8 & 0.5 & 0,8 & 1,5 & 1.9 & 06 & 0.5 & 0.5 & 0.6 & 0.5 & 0.4 \\
\hline Latinota. & 57,4 & 51,8 & 41,3 & 40,9 & 33.1 & 32,8 & 37,5 & 40,3 & 42,3 & 39.2 & 40,3 & 42.1 \\
\hline
\end{tabular}

\section{Cuadro no 1}

Fuente: Comisión del Canal de Panamá (Informes de los ejercicios fiscales: 19851996). Elaboración propia.

Para profundizar en el análisis, desagredo el comercio regional de América Latina y el Caribe vinculado al canal en cinco segmentos, observando los valores de las diversas mercancías a lo largo del período 1985-1996:

\footnotetext{
$4 \quad$ Bisang, R. y Bonvecchi, C. (1996): "La transformación industrial en los noventa. Un proceso con final abierto" en Desarrollo económico, número especial, vol. $36 . \quad$ Buenos Aires. 
1. Comercio entre las costas de Sudamérica: El tonelaje total evoluciona favorablemente por el incremento en todos los rubros en la segunda mitad del período, destacándose los niveles de los dos últimos ejercicios. Si bien lidera este comercio el petróleo crudo, se registra un alto grado de diversificación en la composición de estos tránsitos. Se destacan los embarques de gasoil y gasolina, carbón, fertilizantes, azúcar, carga contenedorizada, menas de alúmina/bauxita, manufacturas de hierro y acero y, metales de hierro, cobre y zinc.

2. Comercio entre Sudamérica y Centroamérica: se registran valores más altos de tonelaje para la segunda mitad del período por un incremento de la mayoría de los rubros. Lideran estos tránsitos los embarques de madera y derivados $y$, los de petróleo y derivados, que registran importantes incrementos en la segunda mitad del período. Destaca, además, el protagonismo del rubro misceláneos, con importantes incrementos, desde 1993, en la carga contenedorizada. Se tiende a incrementar la diversificación ya que en la segunda mitad del período cobran importancia los embarques de fertilizantes, azúcar, melazas y, manufacturas de hierro y acero.

3. Comercio entre Sudamérica y las Indias Occidentales: No se detectan cambios tan acentuados y existe mayor heterogeneidad en la evolución de los rubros. El grupo principal es el de petróleo y derivados en el que se registra una importante caída del tonelaje para la segunda mitad del período. Grupos destacados en la primera mitad pierden su peso, caso de pescado refrigerado y madera y derivados. Por el contrario, para la segunda mitad del período se destacan los embarques de fertilizantes, minerales y metales de hierro, manufacturas de hierro y acero, y carga contenedorizada. Destacan los incrementos de estos dos últimos rubros para los dos últimos ejercicios. 
4. Comercio entre Centroamérica y las Indias Occidentales: Los valores en el tonelaje total son muy superiores en la segunda mitad del período. El comportamiento de los rubros es heterogéneo, predominando el registro de acentuados incrementos en la segunda mitad del período. Se mantiene la inicial especialización en derivados de petróleo, compuestos de amoníaco y fertilizantes, azúcar y melazas. Los tonelajes de estos rubros, se incrementan mucho en la segunda mitad del período. Por otra parte, tiende a establecerse una mayor diversificación pues rubros con escasa relevancia en la primera parte del período empiezan a ganar protagonismo en los últimos ejercicios, tal es el caso de manufacturas de hierro y acero, carga contenedorizada, minerales y metales de hierro. Por el contrario, se registra una importante caída para el caso de pescado refrigerado. Es interesante señalar que se registra una creciente participación de las Indias Occidentales en el mercado de derivados del petróleo, a través del Canal, a partir del ejercicio de 1993.

5. Comercio entre las costas de Centroamérica: Se registra una pérdida de tonelaje por caídas en los embarques principales, nitratos fosfatos y potasa, y derivados del petróleo. Por otra parte, puede detectarse una incipiente tendencia favor de una mayor diversificación. Destaca el importante incremento de la carga contenedorizada en los dos últimos ejercicios. 


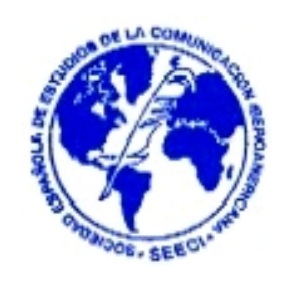

\section{Conclusiones}

Puede afirmarse que, en la segunda mitad del período 1985-1996, se registra una mayor dependencia entre el comercio regional de América Latina y el Caribe y el Canal de Panamá. Además, en los últimos ejercicios, se detectan nuevas tendencias que pudieran acentuar aquella. El aumento de la carga contenedorizada, en vinculación con naves de mayor tamaño y rutas alrededor del mundo, presenta un futuro potencialmente ventajoso para el canal de Panamá. Una de las claves en el futuro del Canal está en la captación de comercio ligero, en consonancia con las transformaciones que se están produciendo en la industria naviera.

El protagonismo que la carga contenedorizada viene teniendo, primeramente para los intercambios entre las costas de Sudamérica y, más recientemente, para el resto de rutas correspondientes al comercio intrarregional, apoya ese favorable futuro para el canal. Además, se registran importantes incrementos para el caso del tonelaje de carga ligera, tal es el caso de manufacturas de hierro y acero. El incremento en el tonelaje para los segmentos identificados en el tráfico intralatinoamericano por el canal es obvio, con la excepción de pérdidas de los flujos entre las costas de Centroamérica y, la estabilidad del comercio entre Sudamérica y las Indias Occidentales. Son relevantes estas tendencias para justificar la adaptación del canal a la demanda. La reciente naturaleza de los procesos de integración en América Latina, impulsados por el Mercosur, tiene su reflejo en el incremento acentuado de los tránsitos entre las dos costas de Sudamérica. Pudiera considerarse que las recientes tendencias son el motor de un incipiente proceso de integración latinoamericano, con los consecuentes efectos sobre el canal.

Aunque se mantiene el protagonismo de rubros tradicionales en estos flujos, las recientes políticas comerciales parecen favorecer el incremento de tales embarques. 


\section{REVISTA DE LA SEECI.}

Fernández Penit, Sara (2000): El canal de Panamá y el comercio regional de América Latina y el Caribe: ¿Futuros dependientes? No 6. Noviembre. Año IV. Páginas: 60-69.

ISSN: 1576-3420 DOI: http://dx.doi.org/10.15198/seeci.2000.6.60-69

Además, se detectan incrementos en tránsitos de mercancías que suponen un mayor valor añadido para el comercio intrarregional. Así, se registra un incremento en el tonelaje de manufacturas de hierro y acero, excepto para las costas de Centroamérica. Es general la tendencia hacia una mayor diversificación en la composición de los comercios diferenciados. 